\title{
Analysis of Hereditary Elliptocytosis with Decreased Binding of Eosin-5-maleimide to Red Blood Cells
}

\author{
Shin-ichiro Suemori, ${ }^{1}$ Hideho Wada, ${ }^{2}$ Hidekazu Nakanishi, ${ }^{2}$ \\ Takayuki Tsujioka, ${ }^{1}$ Takashi Sugihara, ${ }^{2}$ and Kaoru Tohyama ${ }^{1}$ \\ ${ }^{1}$ Department of Laboratory Medicine, Kawasaki Medical School, Kurashiki, Japan \\ ${ }^{2}$ Department of Hematology, Kawasaki Medical School, Kurashiki, Japan \\ Correspondence should be addressed to Shin-ichiro Suemori; suemori@med.kawasaki-m.ac.jp
}

Received 31 January 2015; Revised 2 April 2015; Accepted 13 April 2015

Academic Editor: Aurora M. Cianciarullo

Copyright (C) 2015 Shin-ichiro Suemori et al. This is an open access article distributed under the Creative Commons Attribution License, which permits unrestricted use, distribution, and reproduction in any medium, provided the original work is properly cited.

\begin{abstract}
Flow cytometric test for analyzing the eosin-5-maleimide (EMA) binding to red blood cells has been believed to be a specific method for diagnosing hereditary spherocytosis (HS). However, it has been reported that diseases other than HS, such as hereditary pyropoikilocytosis (HPP) and Southeast Asian ovalocytosis (SAO), which are forms in the category of hereditary elliptocytosis (HE), show decreased EMA binding to red blood cells. We analyzed EMA binding to red blood cells in 101 healthy control subjects and $42 \mathrm{HS}$ patients and obtained a mean channel fluorescence (MCF) cut-off value of 36.4 (sensitivity 0.97 , specificity 0.95 ). Using this method, we also analyzed $12 \mathrm{HE}$ patients. Among them, four HE patients showed the MCF at or below the cut-off value. It indicates that some HE patients have decreased EMA binding to red blood cells. Two of these four HE patients were classified as common HE, and two were spherocytic HE with reduced spectrin. This study demonstrates that, in addition to patients with HPP or SAO, some HE patients have decreased EMA binding to red blood cells.
\end{abstract}

\section{Introduction}

Eosin-5-maleimide (EMA) is a fluorochrome that primarily binds to band 3 of red blood cell membrane proteins. EMA binding decreases in hereditary spherocytosis (HS), which is considered to be a useful finding for the diagnosis of HS [16]. Moreover, among patients with red blood cell membrane abnormalities other than HS, some patients with hereditary pyropoikilocytosis (HPP) and Southeast Asian ovalocytosis (SAO), which are forms of hereditary elliptocytosis (HE), also show decreased EMA binding to red blood cells $[7,8]$. The etiology of $\mathrm{HE}$ includes abnormalities in membrane proteins involved in formation of the membrane structure, including spectrin, protein 4.1 (P4.1), and glycophorin C. HE is basically classified into 5 forms: common HE, spherocytic HE, HPP, $\mathrm{SAO}$, and HE with X chromosome abnormality, based on differences in pathological conditions [9]. There have been few studies examining EMA binding to red blood cells in the HE patients, other than HPP and SAO, and the results are variable $[1,3-5]$. We analyzed EMA binding to red blood cells in $12 \mathrm{HE}$ patients observed in our department and examined the relationship between the types of HE and EMA binding to red blood cells.

\section{Subjects and Methods}

All red blood cells were obtained following informed consent. And all patients gave written informed consent. The study involved $12 \mathrm{HE}$ and $42 \mathrm{HS}$ patients examined in our department between December 2008 and June 2012; 101 healthy subjects were used as a control group. A diagnosis of HS and HE was based on a complete blood count, biochemical analysis, family analysis, red blood cell morphology using scanning electron microscopy (SEM), red blood cell membrane protein analysis using sodium dodecyl sulfate-polyacrylamide gel electrophoresis (SDS-PAGE), and EMA binding to red blood cells. The analyses of all $12 \mathrm{HE}$ patients were requested by other institutions. And the osmotic fragility test was not performed in any patients at client institutions. This study 
was approved by the Research Ethics Committee of Kawasaki Medical School and Hospital.

2.1. Evaluation of Peripheral Red Blood Cell Morphology. Fresh venous blood was drawn to evaluate red blood cell morphology from peripheral blood. A sample was fixed with $0.1 \mathrm{M}$ phosphate buffer with $1 \%$ glutaraldehyde $(\mathrm{pH}$ 7.4) and observed using a scanning electron microscope (S3400 N, HITACHI High-Technologies Corporation). HE can be largely classified into either rod-shaped or ovalocytic based on differences in the degree of red blood cell ovalization. In this study, red blood cells with long diameter/short diameter $\geq 2$ were defined as rod-shaped, those with long diameter/short diameter $<2$ were defined as ovalocytic, and the percentages of the rod-shaped and ovalocytic types in 100 randomly observed red blood cells were calculated.

2.2. Analysis of EMA Binding to Red Blood Cells. Based on the original method of King et al. [1], red blood cells were washed with phosphate buffer saline (PBS) four times in a microtube; after that, 5 volumes of EMA $(5 \mathrm{mg} / \mathrm{mL}$ ) were added to 1 volume of packed red blood cells, and the sample was mixed well. It was then incubated for 1 hour at room temperature in the dark to allow EMA to bind to the red blood cells. After EMA binding, the sample was centrifuged at 13,000 rpm for 10 seconds, the supernatant was removed, and the sample was washed with $0.5 \%$ bovine serum albumin (BSA)/PBS. After repeating this procedure three times, the sample was diluted in a $0.5 \%$ BSA/PBS in a final ratio of $14: 1$ packed red blood cells. Thereafter, flow cytometry was performed using the FL-1 channel at an event count of 15,000 using a FACSCalibur Flow Cytometer (Becton Dickinson), and fluorescence intensity values were obtained as mean channel fluorescence (MCF). MCF was measured three times for each sample, and the mean value was used.

2.3. Preparation of Red Blood Cell Ghost. Red blood cell ghosts were prepared according to the method of Dodge et al. [10]. Ethylenediaminetetraacetic acid (EDTA) and phenylmethylsulfonyl fluoride (PSMF) were added as protease inhibitors to lysis buffer $\left(5 \mathrm{mmol} / \mathrm{L} \mathrm{Na}_{2} \mathrm{HPO}_{4}, 1 \mathrm{mmol} / \mathrm{L}\right.$ EDTA, and $0.2 \mathrm{mmol} / \mathrm{L}$ PMSF [pH 8.0]). After washing three times with $0.9 \% \mathrm{NaCl}, 30$ volumes of lysis buffer were added to 1 volume of packed cells, which was allowed to stand for 5 minutes at $4^{\circ} \mathrm{C}$ to perform hypotonic hemolysis. Then, the sample was centrifuged at $30,000 \times \mathrm{g}$ for 10 minutes at $4^{\circ} \mathrm{C}$ to separate red blood cell membrane protein and hemoglobin; and the hemoglobin component in the supernatant was removed by aspiration. These steps were repeated six to seven times to extract the red blood cell white ghost, which was used as a red blood cell membrane protein sample for subsequent examinations.

2.4. Separation and Evaluation of Red Blood Cell Membrane Protein. Each red blood cell membrane protein fraction was separated by SDS-PAGE using the Fairbanks technique [11] $(3.5 \%$ to $17 \%$ exponential gradient gel: acrylamide $=$ $35: 8$ ). After SDS-PAGE, each membrane protein fraction

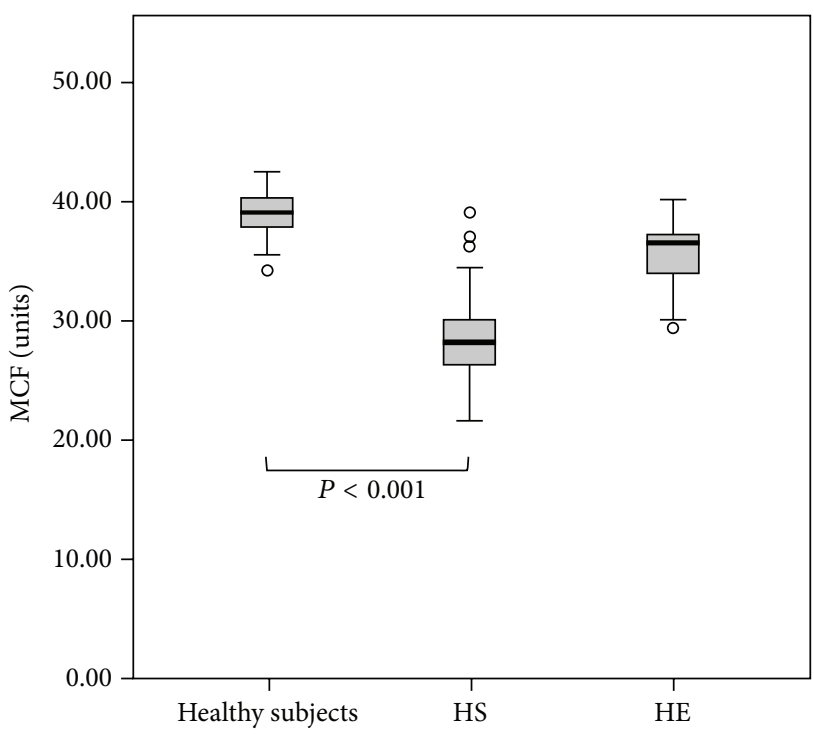

FIGURE 1: EMA binding in healthy subjects, HS patients, and HE patients. MCF in healthy subjects $=39.2 \pm 1.6(n=101), \mathrm{MCF}$ in HS patients $=28.8 \pm 3.8(n=42)$, and MCF in HE patients $=35.6 \pm 3.3$ $(n=12)$ (MCF cut-off value: 36.4 ).

was identified by staining the gel with Coomassie brilliant blue R-250. After the gel was dried, the absorbance of each band was measured using densitometer (GS-800 Calibrated Densitometer, Bio-Rad). Then, results were analyzed by Quantity One software (Bio-Rad). Each band, representing a membrane protein fraction, is presented as a ratio to the combined density of the total membrane fraction (bands 1-7). Membrane protein deficiency was determined when patients had $\geq 10 \%$ and $\geq 2$ standard deviation difference relative to the mean stain density for each fraction in healthy control subjects $(n=3)$; controls were run on the same gel as the study subjects. Protein concentration was measured at $655 \mathrm{~nm}$ using the DC Protein Assay Kit (Bio-Rad) based on the Lowry technique, and $25 \mu \mathrm{g}$ of red blood cell membrane protein was used for electrophoresis [12].

2.5. Statistical Analysis. Significant differences were tested by the Mann-Whitney $U$ test. Analysis and construction of receiver operating characteristic (ROC) curves were accomplished using SPSS Statistics version 20.0 (IBM).

\section{Results}

3.1. Analysis of EMA Binding to Red Blood Cells in Healthy Subjects, HS Patients, and HE Patients. Using ROC curves of MCF values for EMA binding to red blood cells, the cutoff value in HS patients was 36.4 (sensitivity 0.97 , specificity $0.95)$. MCF values below this value were defined as decreased EMA binding to red blood cells. Four of $12 \mathrm{HE}$ patients showed decreased EMA binding (Figure 1, Table 1).

3.2. Association between EMA Binding and HE Types (Table 1). Based on SEM findings, elliptocytes were present in addition 


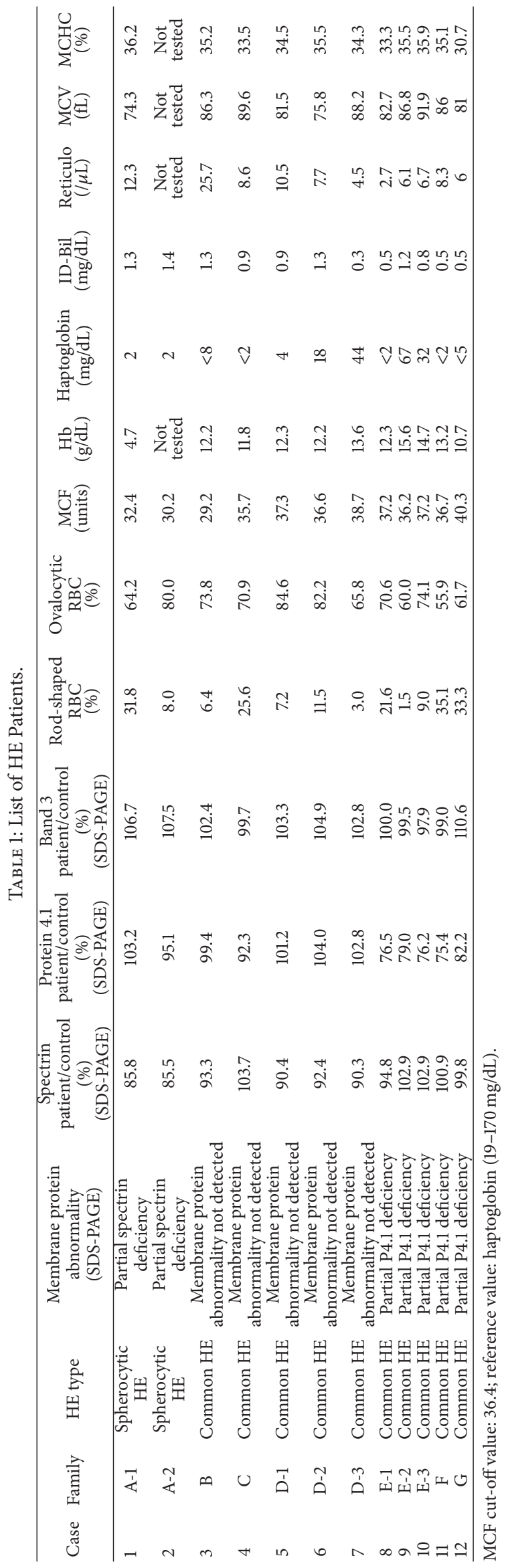




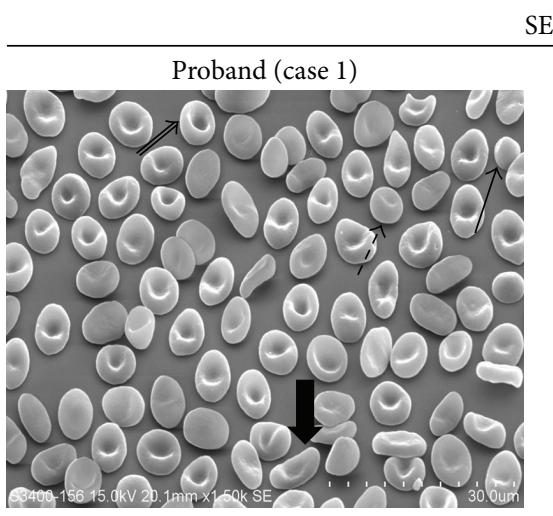

$$
\underset{\text { Spherocyte }}{\longleftarrow-\text { Stomatospherocyte }} \Longleftarrow \text { Stomatocyte } \longleftarrow \text { Spherocyte } \longleftarrow \text { Stliptocyte } \longleftarrow-\text { Stomatospherocyte } \Longleftarrow \text { Elliptocyte }
$$

(a)
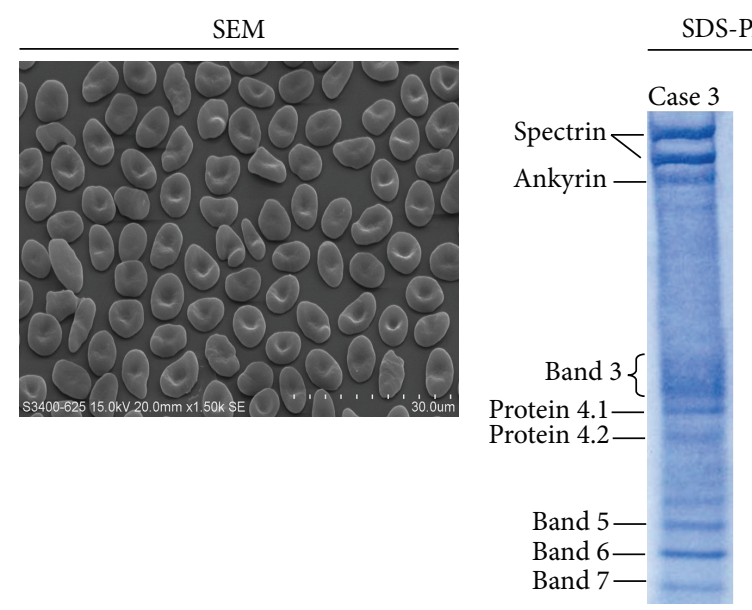

(b)
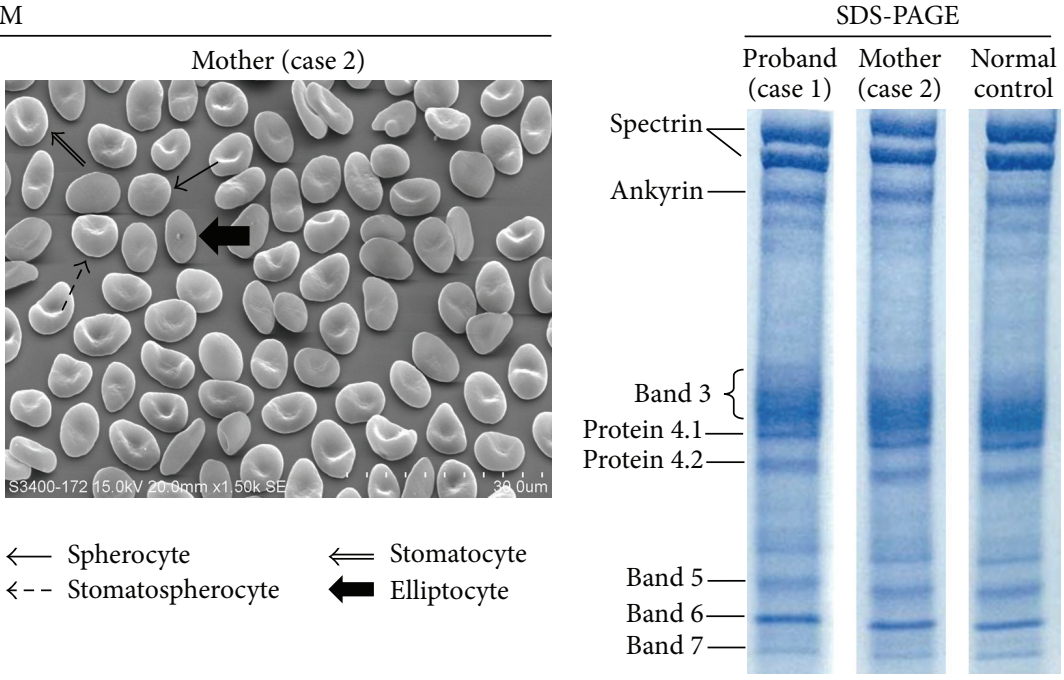
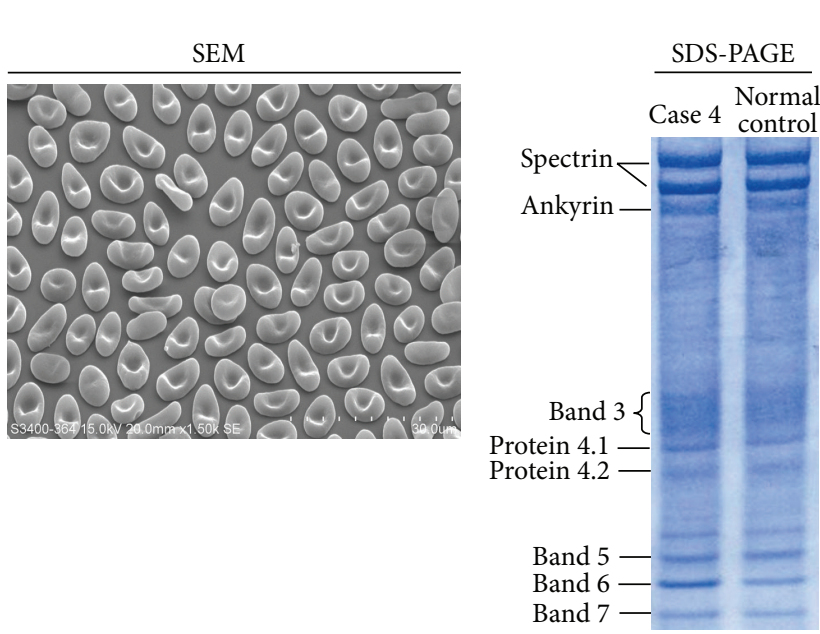

(c)

FIGURE 2: SEM images and results of SDS-PAGE gels of HE patients with decreased EMA binding to red blood cells. (a) SEM image and SDS-PAGE of Family A (case 1, case 2). SDS-PAGE: proband (case 1): spectrin 14.2\% reduction, mother (case 2): spectrin $14.5 \%$ reduction. (b) SEM image and SDS-PAGE of case 3. SEM: ovalocytic type and rod-shaped type were observed. SDS-PAGE: no membrane protein abnormality detected. (c) SEM image and SDS-PAGE of case 4. SEM: many rod-shaped types were observed. SDS-PAGE: no membrane protein abnormality detected.

to the findings observed in HS such as spherocyte development and decreased spectrin in cases 1 and 2. So these cases were diagnosed with spherocytic HE, not HS (Figure 2(a)). These two cases demonstrated decreased EMA binding to red blood cells.

SEM findings also showed that 10 other HE patients had common HE. Among them, two showed decreased EMA binding (Figures 2(b) and 2(c)).

3.3. Association between EMA Binding and Red Blood Cell Membrane Protein Abnormalities in HE Patients (Table 1). Red blood cell membrane protein analysis in $12 \mathrm{HE}$ patients indicated that two had partial spectrin deficiency and five had partial P4.1 deficiency. Two patients with partial spectrin deficiency (cases 1 and 2) showed decreased EMA binding (Figure 2(a)). No patients with partial P4.1 deficiency showed decreased EMA binding. In addition, two patients (cases 3 and 4) clearly showed elliptocytosis with decreased EMA binding to red blood cells. However, no abnormalities in membrane proteins (Figures 2(b) and 2(c)) were detected.

No significant decrease in band 3 was detected by SDSPAGE in four patients with decreased EMA binding.

3.4. Association between EMA Binding and Red Blood Cell Ovalization in HE Patients. Red blood cells with long diameter/short diameter $\geq 2$ were defined as rod-shaped, and those with long diameter/short diameter $<2$ were defined as ovalocytic. The percentages of the rod-shaped and ovalocytic types in 100 red blood cells on SEM images were calculated. The results showed that the rod-shaped type comprised $18.0 \%$ $\pm 12.7 \%$ in four HE patients with decreased EMA binding and 


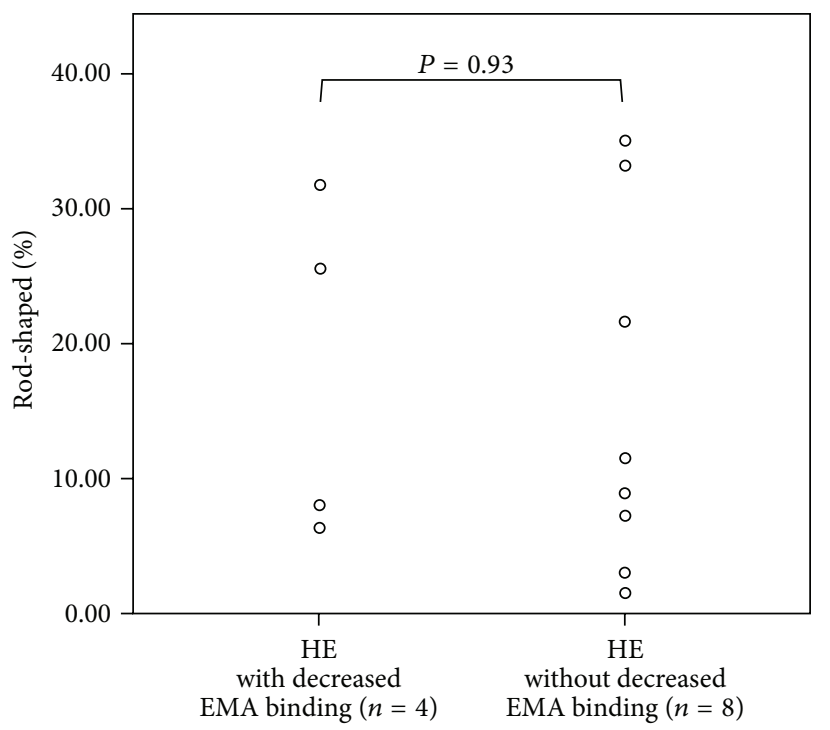

(a)

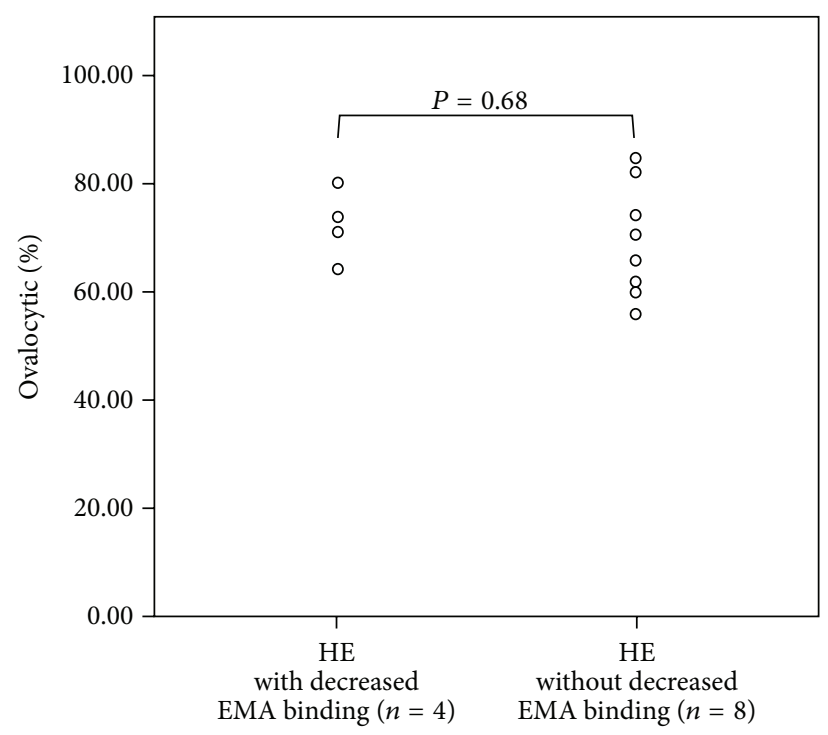

(b)

FIGURE 3: Association between the presence/absence of decreased EMA binding and elliptocyte development in HE patients. (a) Association between the presence/absence of decreased EMA binding and the percentage of rod-shaped type in HE patients. The percentage of rod-shaped type in $4 \mathrm{HE}$ patients with decreased EMA binding $=18.0 \pm 12.7 \%$. The percentage of rod-shaped type in $8 \mathrm{HE}$ patients without decreased EMA binding $=15.3 \pm 13.2 \%$. Rod-shaped type: RBC long diameter/short diameter $\geq 2$. (b) Association between the presence/absence of decreased EMA binding and the percentage of ovalocytic type in HE patients. The percentage of the ovalocytic type in 4 HE patients with decreased EMA binding $=72.2 \pm 6.6 \%$. The percentage of the ovalocytic type in 8 HE patients without decreased EMA binding $=69.4 \pm 10.4 \%$. Ovalocytic type: RBC long diameter/short diameter $<2$.

$15.3 \% \pm 13.2 \%$ in eight HE patients with normal EMA binding. Therefore, no clear correlation was observed between decreased EMA binding and the ratio of rod-shape type (Figure 3(a)). The ovalocytic type comprised $72.2 \% \pm 6.6 \%$ in four HE patients with decreased EMA binding and 69.4\% $\pm 10.4 \%$ in eight HE patients with normal EMA binding. Thus, these results indicate no clear correlation between decreased EMA binding and the ratio of the ovalocytic type (Figure 3(b)).

\section{Discussion}

In the present study, four HE patients demonstrated decreased EMA binding. Among them, two were spherocytic HE with spectrin abnormalities. Spectrin abnormalities can also cause HS as well as HE. For example, genetic mutations mainly causing decreased spectrin are common in HS [13], whereas mutations causing abnormalities in spectrin selfassociation are common in HE [14]. These two patients had partial spectrin deficiency, as observed in some patients with HS. Spherocytic HE has the features of both HS and HE. So it is suggested that the decreased EMA binding observed in two spherocytic HE patients might have exhibited the features of HS.

In this study, decreased EMA binding to red blood cells was observed in two patients with common HE in whom no membrane protein abnormalities were detected by SDSPAGE.

Considering various degrees of red blood cell ovalization among HE patients, we examined differences in the trend of ovalization as factors involved in decreased EMA binding. However, no association was observed between the degree of ovalization and EMA binding. The mechanism underlying the decrease in EMA binding to red blood cells in these patients is unknown.

This study revealed that some HE patients, other than those with HPP or SAO, present with decreased EMA binding to red blood cells. The EMA binding test is believed to be a specific method for diagnosing HS. However, it should be noted that decreased EMA binding can be observed even in some HE patients similarly to HS patients. Historically, congenital hemolytic anemia induced by red cell membrane abnormalities was defined based on their characteristic red blood cell shape [15]. The HS guidelines revised in 2011 [16] show that the EMA binding test is useful for screening atypical HS patients. However, attention should be paid to the presence of patients with spherocytic HE or common HE with decreased EMA binding.

\section{Conflict of Interests}

The authors declare that there is no conflict of interests regarding the publication of this paper.

\section{Acknowledgments}

The authors thank Yoshihito Yawata, M.D., Ph.D., for advice. And the authors thank Ms. Sakura Eda for assistance of SDSPAGE and SEM. This study was supported by a Kawasaki Medical School project grant. 


\section{References}

[1] M.-J. King, J. Behrens, C. Rogers, C. Flynn, D. Greenwood, and K. Chambers, "Rapid flow cytometric test for the diagnosis of membrane cytoskeleton-associated haemolytic anaemia," British Journal of Haematology, vol. 111, no. 3, pp. 924-933, 2000.

[2] M.-J. King, J. S. Smythe, and R. Mushens, "Eosin-5-maleimide binding to band 3 and Rh-related proteins forms the basis of a screening test for hereditary spherocytosis," British Journal of Haematology, vol. 124, no. 1, pp. 106-113, 2004.

[3] M.-J. King, P. Telfer, H. MacKinnon et al., "Using the Eosin-5maleimide binding test in the differential diagnosis of hereditary spherocytosis and hereditary pyropoikilocytosis," Cytometry Part B: Clinical Cytometry, vol. 74, no. 4, pp. 244-250, 2008.

[4] F. Girodon, L. Garçon, E. Bergoin et al., "Usefulness of the eosin5/-maleimide cytometric method as a first-line screening test for the diagnosis of hereditary spherocytosis: comparison with ektacytometry and protein electrophoresis," British Journal of Haematology, vol. 140, no. 4, pp. 468-470, 2008.

[5] P. Bianchi, E. Fermo, C. Vercellati et al., "Diagnostic power of laboratory tests for hereditary spherocytosis: a comparison study in 150 patients grouped according to molecular and clinical characteristics," Haematologica, vol. 97, no. 4, pp. 516523, 2012.

[6] R. L. Crisp, L. Solari, D. Vota et al., "A prospective study to assess the predictive value for hereditary spherocytosis using five laboratory tests (cryohemolysis test, eosin- $5^{\prime}$-maleimide flow cytometry, osmotic fragility test, autohemolysis test, and SDSPAGE) on 50 hereditary spherocytosis families in Argentina," Annals of Hematology, vol. 90, no. 6, pp. 625-634, 2011.

[7] M.-J. King, M. A. Jepson, A. Guest, and R. Mushens, "Detection of hereditary pyropoikilocytosis by the eosin-5-maleimide (EMA)-binding test is attributable to a marked reduction in EMA-reactive transmembrane proteins," International Journal of Laboratory Hematology, vol. 33, no. 2, pp. 205-211, 2011.

[8] M.-J. King, L. Bruce, and A. Whiteway, "The mutant erythrocyte band 3 protein in Southeast Asian ovalocytosis does not bind eosin-5-maleimide," International Journal of Laboratory Hematology, vol. 31, no. 1, pp. 116-117, 2009.

[9] "Disorders of the red blood cell membrane," in Blood: Principles and Practice of Hematology, R. I. Handin, S. E. Lux IV, and T. P. Stossel, Eds., pp. 1715-1809, Lippincott Williams \& Wilkins, Philadelphia, Pa, USA, 2nd edition, 2003.

[10] J. T. Dodge, C. Mitchell, and D. J. Hanahan, “The preparation and chemical characteristics of hemoglobin-free ghosts of human erythrocytes," Archives of Biochemistry and Biophysics, vol. 100, no. 1, pp. 119-130, 1963.

[11] G. Fairbanks, T. L. Steck, and D. F. H. Wallach, "Electrophoretic analysis of the major polypeptides of the human erythrocyte membrane," Biochemistry, vol. 10, no. 13, pp. 2606-2617, 1971.

[12] O. H. Lowry, N. J. Rosebrough, A. L. Farr, and R. J. Randall, "Protein measurement with the Folin phenol reagent," The Journal of Biological Chemistry, vol. 193, no. 1, pp. 265-275, 1951.

[13] "Disorders of the red blood cell membrane," in Blood. Principles and Practice of Hematology, R. I. Handin, S. E. Lux IV, and T. P. Stossel, Eds., pp. 1754-1760, Lippincott Williams \& Wilkins, Philadelphia, Pa, USA, 2nd edition, 2003.

[14] "Disorders of the red blood cell membrane," in Blood. Principles and Practice of Hematology, R. I. Handin, S. E. Lux IV, and T. P. Stossel, Eds., pp. 1799-1805, Lippincott Williams \& Wilkins, Philadelphia, Pa, USA, 2nd edition, 2003.
[15] "Hereditary spherocytosis, hereditary elliptocytosis, and other disorders associated with abnormalities of the erythrocyte membrane," in Wintrobe's Clinical Hematology, J. P. Greer, J. Foerster, G. M. Rodgers, F. Paraskevas, B. Glader, and D. A. Arber, Eds., pp. 911-932, Lippincott Williams \& Wilkins, Philadelphia, Pa, USA, 12th edition, 2009.

[16] P. H. B. Bolton-Maggs, J. C. Langer, A. Iolascon, P. Tittensor, and M.-J. King, "Guidelines for the diagnosis and management of hereditary spherocytosis-2011 update," British Journal of Haematology, vol. 156, no. 1, pp. 37-49, 2012. 


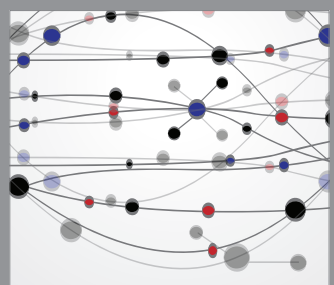

The Scientific World Journal
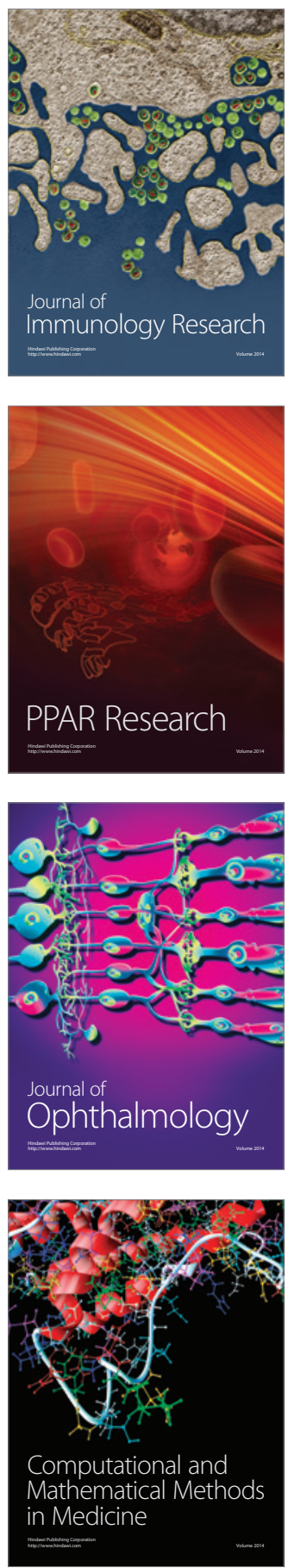

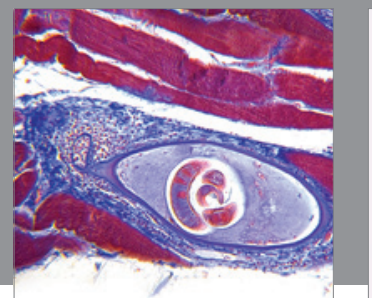

Gastroenterology

Research and Practice
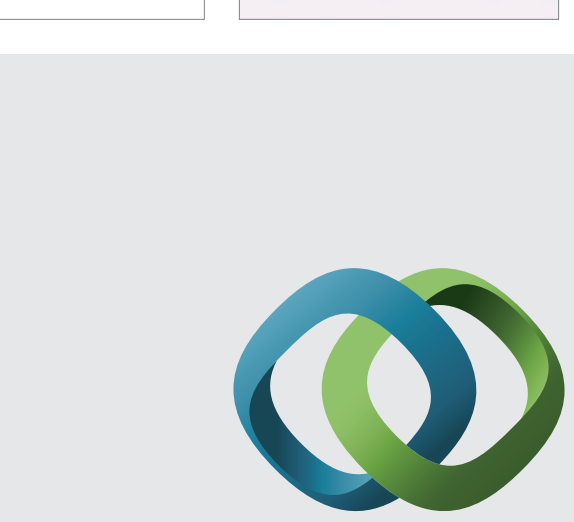

\section{Hindawi}

Submit your manuscripts at

http://www.hindawi.com
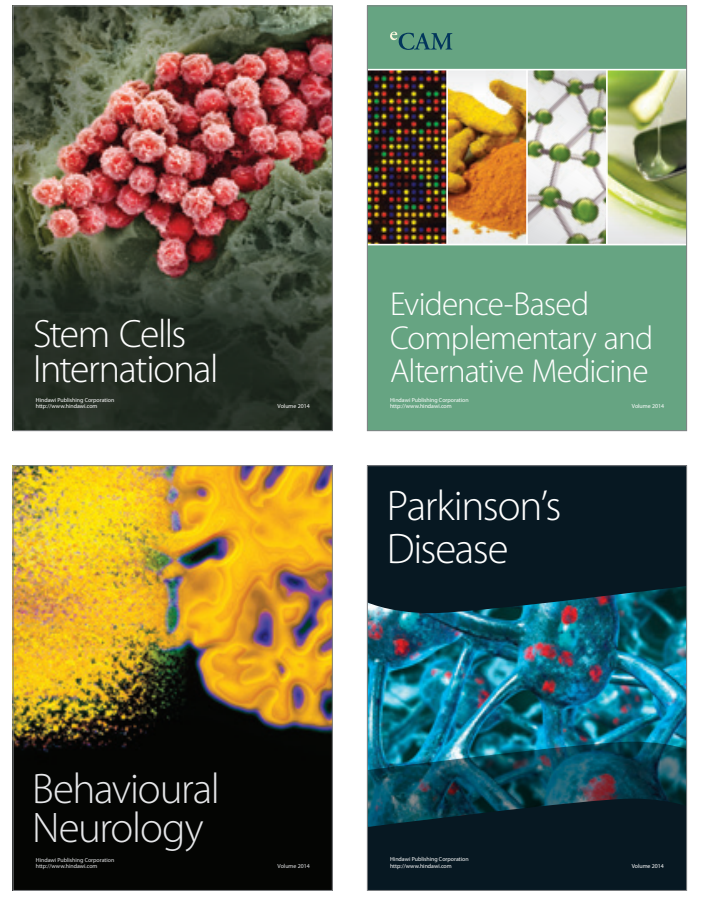
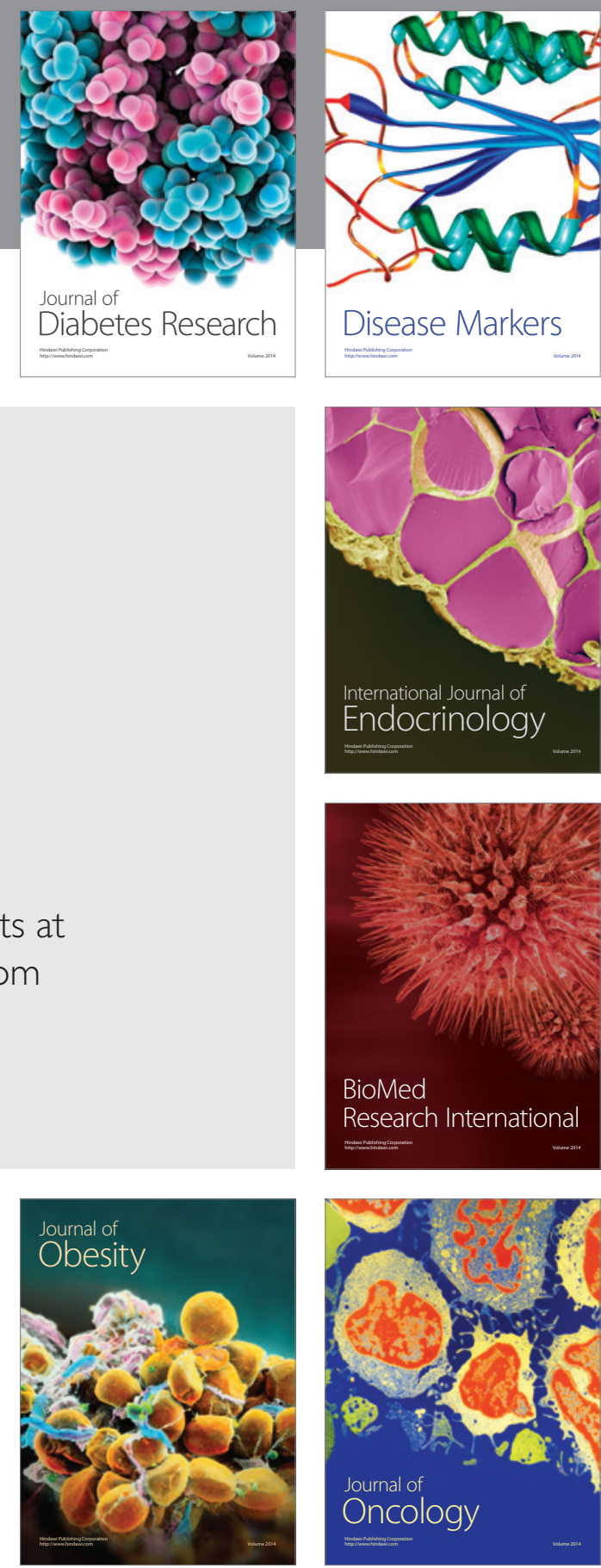

Disease Markers
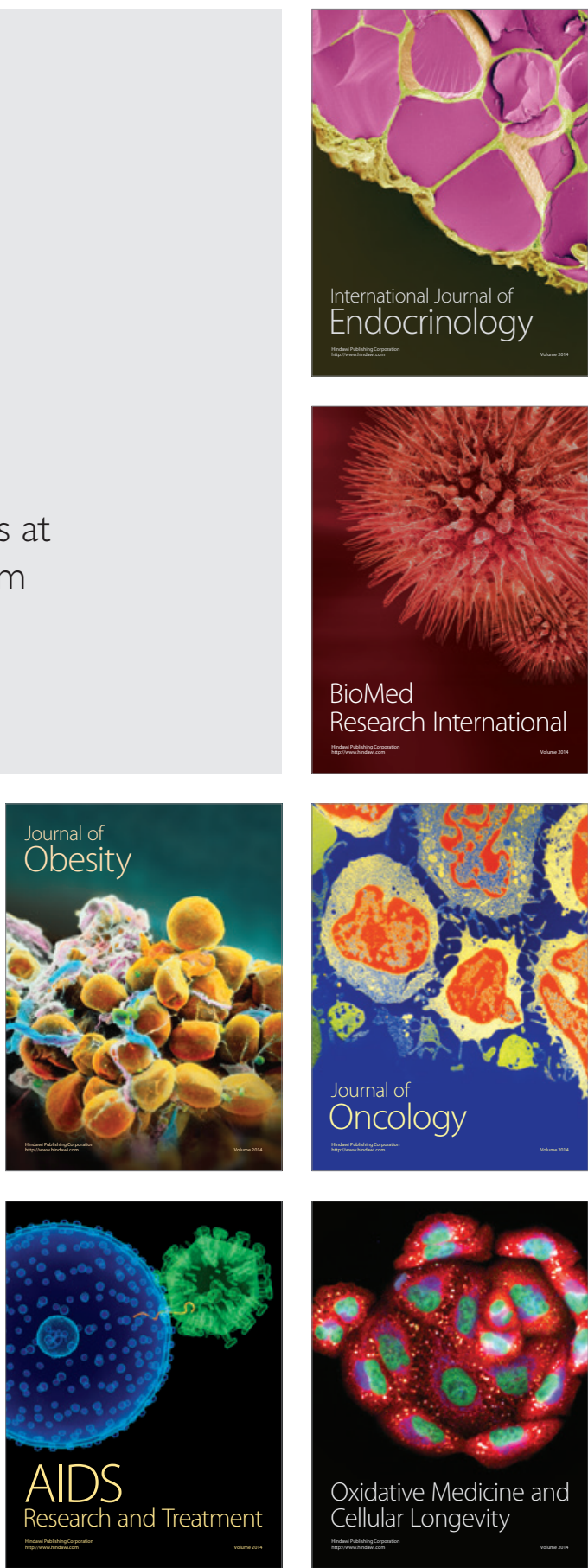